\title{
Iodinated Contrast Media and Their Adverse Reactions*
}

Jagdish Singh and Aditya Daftary

Teleradiology Solutions, Bangalore, India

Cross-use of technology between nuclear medicine and radiology technologists is expanding. The growth of PET/CT and the increasing use of intravenous contrast agents during these procedures bring the nuclear medicine technologist into direct contact with these agents and their associated complications. A basic understanding of the occurrence, risk factors, clinical features, and management of these procedures is of increasing importance to the nuclear medicine technologist. After reading this article, the technologist will be able to list the factors that increase the risk of contrast reactions; understand ways to minimize the occurrence of contrast reactions; and develop a plan to identify, treat, and manage the reactions effectively.

Key Words: iodinated contrast media; contrast reactions

J Nucl Med Technol 2008; 36:69-74

DOI: 10.2967/jnmt.107.047621

I

odinated contrast media are among the most commonly used injectables in radiology today. Modern iodinated contrast agents can be used almost anywhere in the body. Most often they are used intravenously but can be administered intraarterially, intrathecally, and intraabdominally. They are usually safe, and adverse effects are generally mild and self-limiting. Nonetheless, severe or life-threatening reactions can occur.

Radiologists and other medical personnel involved with the use of iodinated contrast agents must be aware of the risk factors for reactions to contrast media. They should be aware of and use strategies to minimize adverse events and be prepared to promptly recognize and manage them (1).

\section{THE CHEMISTRY OF IODINATED CONTRAST MEDIA}

All the currently used contrast media are chemical modifications of a 2,4,6-triiodinated benzene ring. They are classified on the basis of their physical and chemical char-

\footnotetext{
Received Sep. 27, 2007; revision accepted Dec. 13, 2007.

For correspondence or reprints contact: Aditya Daftary, Teleradiology Solutions, Plot 7G, Vishweshwaraiya Industrial Complex, Opposite Graphite India, ITPL Main Rd., Whitefield, Bangalore, India 560048.

E-mail: Aditya.daftary@telradsol.com

*NOTE: FOR CE CREDIT, YOU CAN ACCESS THIS ACTIVITY THROUGH

THE SNM WEB SITE (http://www.snm.org/ce_online) THROUGH JUNE 2010.

COPYRIGHT @ 2008 by the Society of Nuclear Medicine, Inc.
}

acteristics, including their chemical structure, osmolality, iodine content, and ionization in solution $(2,3)$.

The parent molecule from which the contrast agents are derived is benzene. This is a toxic water-insoluble liquid. The carbon atoms on a benzene ring are numbered clockwise from 1 to 6 . Benzoic acid is produced by introducing an acid group at position 1 on the benzene ring. This acid group permits the formation of salts or amides, which influence water solubility. 2,4,6-triiodobenzoic acid is obtained by introducing iodine atoms at positions 2,4 , and 6 on the ring. Iodine is the element used in contrast media as it possesses 3 important properties essential for the production of contrast media: high-contrast density, firm binding to the benzene molecule, and low toxicity. Triiodobenzoic acid is made less toxic and less lipophilic (fatsoluble) by introducing side chains at positions 3 and 5 (3).

\section{OSMOLALITY, VISCOSITY, AND IONICITY}

Because of their chemical properties, contrast media are usually thicker (viscosity) and have greater osmolality (more molecules per kilogram of water) than blood, plasma, or cerebrospinal fluid. Viscosity and osmolality play a part in the development of contrast reactions.

Ionicity is the characteristic of a molecule to break up into a positively charged cation and a negatively charged anion, resulting in more molecules per kilogram of water and thus increasing osmolality. Nonionic agents do not have this property and hence are less osmolar.

Ionic and nonionic contrast media may be monomeric or dimeric. Typically, 3 iodine atoms are delivered with each benzene ring of a contrast medium. If a contrast molecule contains only 1 benzene ring, it is called a monomer. To deliver more iodine with each molecule of contrast, 2 benzene rings may be combined to produce a dimer. This molecule would deliver 6 iodine atoms with each molecule.

In a solution, ionic monomers break up into their anion and cation components (increasing osmolality), delivering 3 iodine atoms (a 2:3 ratio of osmolar particles to iodine), whereas ionic dimers would deliver 2 ionic components per 6 iodine atoms (ratio, 1:3). Nonionic monomers do not break up in solution; a single molecule delivers 3 iodine atoms (ratio, 1:3), whereas a single nonionic dimer delivers 6 iodine atoms (ratio, 1:6). Thus, nonionic dimers are the 
TABLE 1

Commonly Used lodinated Contrast Media

\begin{tabular}{|c|c|c|c|}
\hline Name & Type & lodine content $(\mathrm{mg} / \mathrm{mL})$ & Osmolality \\
\hline \multicolumn{4}{|l|}{ Ionic } \\
\hline Diatrizoate (Hypaque 50; GE Healthcare) & Monomer & 300 & 1,550 (high) \\
\hline Metrizoate Isopaque (Coronar 370; Nycomed A/S) & Monomer & 370 & 2,100 (high) \\
\hline loxaglate (Hexabrix; Mallinckrodt, Inc.) & Dimer & 320 & 580 (low) \\
\hline \multicolumn{4}{|l|}{ Nonionic } \\
\hline lopamidol (Isovue-370; Bracco Diagnostics Inc.) & Monomer & 370 & 796 (low) \\
\hline lohexol (Omnipaque 350; GE Healthcare) & Monomer & 350 & 884 (low) \\
\hline lodixanol (Visipaque 320; GE Healthcare) & Dimer & 320 & 290 (iso) \\
\hline
\end{tabular}

most ideal contrast agents as they deliver the most iodine with the least effect on osmolality.

High-osmolality contrast media (HOCM) have 5-8 times the osmolality of plasma; low-osmolality contrast media (LOCM) have 2-3 times the osmolality of serum; and isoosmolar contrast media, which are increasingly used, have the same osmolality as blood, plasma, and cerebrospinal fluid.

The incidence of mild and moderate contrast reactions is higher for HOCM $(6 \%-8 \%)$ than for LOCM $(0.2 \%)$, but the incidence of severe reactions remains similar. Anaphylactoid reactions are more common while using HOCM, whereas cardiovascular decompensation is more common while using LOCM (4). Commonly used iodinated contrast media and their characteristics are summarized in Table 1.

\section{ADVERSE REACTIONS AND THEIR ETIOLOGY}

Millions of radiology studies are performed with intravascular contrast each year. Like all other pharmaceuticals, however, these agents are not completely devoid of risks, and adverse side effects can occur (5-8). Reactions are infrequent and range from $5 \%$ to $12 \%$ for HOCM and from $1 \%$ to $3 \%$ for LOCM (7).

A detailed knowledge of the variety of side effects and their likelihood in relationship to preexisting conditions and treatment is required to ensure optimal patient care. The following discussion will assist radiologists, physicians, and technologists dealing with contrast media in recognizing and managing contrast-induced reactions.

\section{RISK FACTORS FOR CONTRAST REACTIONS}

Many of the factors that may increase the risk of a contrast reaction are summarized in Table 2. Although it is not guaranteed that a reaction will develop, it is important to stay alert for any reactions these patients might exhibit $(4,5,9)$.

\section{ETIOLOGY OF CONTRAST REACTIONS}

There are 2 basic types of contrast reactions; the first is the anaphylactoid or idiosyncratic, and the second is the nonanaphylactoid. Contrast reactions may occur from either one or a combination of both of these effects.

\section{Anaphylactoid/Idiosyncratic Reactions}

As the name suggests, the exact etiology for these reactions is less well understood, and they tend to mimic an anaphylactic (allergic) reaction. The proposed mechanism of these reactions includes enzyme induction, causing the release of vasoactive substances such as histamine and serotonin and the activation of a physiologic cascade and eventually the complement system (10).

These are the most frequent type of adverse reactions and may have serious, occasionally fatal, complications. These reactions are more frequent in patients with asthma (5 times), patients with previous reactions (4-6 times), patients with cardiovascular and renal disease, and individuals on $\beta$-blockers. Anxiety, apprehension, and fear may play a part in this type of reaction. Such reactions usually begin within 20 min of injection and are independent of the dose administered. Symptoms associated with anaphylactoid reactions are classified as mild (skin rash, itching, nasal discharge, nausea, and vomiting), moderate (persistence of mild symptoms, facial or laryngeal edema, bronchospasm, dyspnea, tachycardia, or bradycardia), and severe (lifethreatening arrhythmias, hypotension, overt bronchospasm, laryngeal edema, pulmonary edema, seizure, syncope, and death) $(11,12)$.

TABLE 2

Common Factors Predisposing Patient to Contrast Reactions

\begin{tabular}{cc}
\hline \multicolumn{1}{c}{ Factor } & Predisposing characteristic \\
\hline Age & Infants and those older than $60 \mathrm{y}$ \\
Sex & Females $>$ males \\
Underlying medical & Asthma, heart disease, dehydration, \\
conditions & renal disease, diabetes \\
Hematologic & Myeloma, sickle cell disease, \\
conditions & polycythemia \\
Medications & NSAIDs, IL-2, $\beta$-blockers, \\
& biguanides \\
Contrast-related & $>20$ mg iodine, faster injection rate, \\
& intraarterial, previous contrast \\
& reactions
\end{tabular}

NSAIDs = nonsteroidal antiinflammatory drugs; IL-2 = interleukin-2. 


\section{Nonanaphylactoid Reactions}

Nonanaphylactoid reactions are also called physiochemotoxic or nonidiosyncratic reactions (13). These reactions are believed to result from the ability of the contrast media to upset the homeostasis of the body, especially the blood circulation. These reactions are dependent on the physical properties of the contrast medium such as ionicity (which causes free ions in the circulation, which in turn may disrupt electrical charges associated with nervous or cardiac activity) and osmolality (which causes large shifts in fluid volumes). Increasing iodine concentration also increases the risk of these reactions. Finally, the volume and route of administration of contrast also increase the likelihood of such reactions (larger volume or intraarterial administration are more likely to produce a reaction) $(1,14)$.

The cardiovascular, respiratory, urinary, gastrointestinal, and nervous systems are most commonly affected by physiologic changes produced by contrast media. The symptoms of nonanaphylactoid reactions are warmth, metallic taste, nausea, vomiting, bradycardia, hypotension, vasovagal reactions, neuropathy, and delayed reactions ( 1 ).

\section{MANAGEMENT OF CONTRAST REACTIONS}

Patient selection and preparation and the actual management of reactions when they occur are 2 essential components in the management of contrast reactions.

\section{Patient Selection, Preparation, and Special Circumstances}

Before administering contrast media, one should assess the medical history for factors predisposing a patient to contrast reactions. These factors are summarized in Table 2 . It should be noted that none of the conditions listed in Table 2 is an absolute contraindication to administering contrast. Consultation with the referring physician and radiologist, on a per-case basis, is necessary to develop guidelines that are in the patient's best interests.

Once the decision to administer contrast has been made, secure access should be obtained. The bore of the catheter should be determined by the rate at which contrast is to be administered and tested with an appropriate saline bolus immediately before injection. All air leaks and bubbles should be removed from the injecting system.

Patient reassurance plays an important role in minimizing contrast reactions. A step-by-step explanation of the procedure with expected changes (a mild warm flushing at the site of injection, which spreads over the body and may be particularly intense in the perineum, and metallic taste that pass away quickly) is reassuring to the patient. Additionally, in the case of nervous patients, encouraging continuous conversation and feedback from the patient during the scan, if possible, is also helpful.

\section{Premedication}

A test dose and compulsory premedication are seldom used in current practice (15). Premedication is considered in those patients who require intravenous contrast but have
TABLE 3

Premedication Protocols for Patients with Previous or Increased Risk for Contrast Reactions

\begin{tabular}{cc}
\hline \multicolumn{1}{c}{ Premedication } & Protocol \\
\hline $\begin{array}{c}\text { Corticosteroids } \\
\text { (any of the following) }\end{array}$ & Prednisone: $50 \mathrm{mg}$ orally, 13,7, \\
& and $1 \mathrm{~h}$ before contrast injection \\
& Hydrocortisone: $200 \mathrm{mg}$ intravenously, \\
& $1 \mathrm{~h}$ before contrast injection \\
& Methylprednisone: $32 \mathrm{mg}$ orally, 12 and \\
& 2 h before contrast media injection \\
Antihistamine & Diphenhydramine: 50 mg \\
(optional) & intravenously/intramuscularly/ \\
& orally $1 \mathrm{~h}$ before contrast injection \\
\hline
\end{tabular}

had previous reactions. Although patients who have shellfish allergies are more prone to contrast reactions, this is more likely caused by cross-reactivity between shellfish and contrast media, rather than by the patient's inherent allergic tendency (similar to the reason why patients with asthma are more prone to reactions) (16). Various premedication protocols involving the use of steroids and antihistaminics are summarized in Table $3(17,18)$. Steroid premedication is relatively contraindicated in active tuberculosis, diabetes mellitus, peptic ulcer disease, acute lymphoblastic leukemia, and non-Hodgkin's lymphoma.

\section{MANAGING COMMON REACTIONS}

\section{Extravasation}

Extravasation can occur during hand or power injection in $0.1 \%-0.9 \%$ of cases but is more common in the latter. The elderly, infants, children, patients with altered consciousness, and those with underlying vascular disease are more prone to extravasation. Small extravasations of contrast

TABLE 4

General Principles for Managing Contrast Reactions

\begin{tabular}{|c|c|}
\hline Principle & Strategy \\
\hline \multirow[t]{4}{*}{ A } & $\begin{array}{l}\text { Assessment (severity and category of reaction): } \\
\text { blood pressure and pulse monitoring, ECG } \\
\text { monitor for evaluation of cardiac rhythm }\end{array}$ \\
\hline & Assistance (call for it) \\
\hline & Airway, oxygen \\
\hline & $\begin{array}{l}\text { Access (venous) _ secure/improve intravenous } \\
\text { lines }\end{array}$ \\
\hline \multirow[t]{2}{*}{ B } & $\begin{array}{l}\text { Breathing (begin cardiopulmonary resuscitation } \\
\text { if necessary, bag-valve mask or mouth mask) }\end{array}$ \\
\hline & $\begin{array}{l}\text { Beware of paradoxical responses (e.g., } \beta \text {-blockers } \\
\text { may prevent tachycardia response) }\end{array}$ \\
\hline \multirow[t]{4}{*}{ C } & Categorize reaction and patient status \\
\hline & Circulatory assistance, intravenous fluids \\
\hline & $\begin{array}{l}\text { Call cardiopulmonary arrest response team if } \\
\text { necessary }\end{array}$ \\
\hline & $\begin{array}{l}\text { Cardiac output assessment, decreased venous } \\
\text { return }\end{array}$ \\
\hline \multirow[t]{2}{*}{ D } & Drugs: dose and route, do not delay \\
\hline & Do monitor, assess, and reassure patients \\
\hline $\mathrm{ECG}=e$ & ctrocardiogram. \\
\hline
\end{tabular}


TABLE 5

Management of Common Contrast Reactions

\begin{tabular}{|c|c|c|c|}
\hline Reaction & Etiology & Monitor... & Treatment (28-30) \\
\hline \multicolumn{4}{|l|}{ Anaphylactoid } \\
\hline Urticaria (skin rash) & $\begin{array}{l}\text { Anaphylactoid } \\
\text { reaction }\end{array}$ & $\begin{array}{l}\text { Initial size with } \\
\text { marking and follow }\end{array}$ & $\begin{array}{l}\text { Usually none; diphenhydramine, } 25-50 \mathrm{mg} \\
\text { orally/intramuscularly/intravenously; } \\
\text { epinephrine }(1: 1,000), 0.1-0.3 \mathrm{~mL} \\
\text { subcutaneously/intramuscularly }\end{array}$ \\
\hline Bronchospasm & $\begin{array}{l}\text { Anaphylactoid } \\
\text { reaction }\end{array}$ & $\begin{array}{l}\text { Oxygen saturation, } \\
\text { pulse, BP }\end{array}$ & $\begin{array}{l}\text { Secure airway; oxygen, } 6-10 \mathrm{~L} / \mathrm{min} \text {; } \\
\text { metaproterenol/terbutaline inhaler, } 2-3 \text { puffs; } \\
\text { epinephrine }(1: 1,000), 0.1-0.3 \mathrm{~mL} \\
\text { subcutaneously/intramuscularly; epinephrine } \\
\text { (1:10,000), } 1 \mathrm{~mL} \text { intravenously (slowly) if } \\
\text { hypotensive; call the emergency medical team }\end{array}$ \\
\hline Facial or laryngeal edema & $\begin{array}{l}\text { Anaphylactoid } \\
\text { reaction }\end{array}$ & $\begin{array}{l}\text { Oxygen saturation, } \\
\text { pulse, BP }\end{array}$ & $\begin{array}{l}\text { Secure airway; oxygen, } 6-10 \mathrm{~L} / \mathrm{min} \text {; call the } \\
\text { emergency medical team if severe; epinephrine } \\
\text { (1:1000), } 0.1-0.3 \mathrm{~mL} \text { subcutaneously/ } \\
\text { intramuscularly; epinephrine ( } 1: 10,000) \\
1 \mathrm{~mL} \text { intravenously (slowly) if hypotensive; } \\
\text { call the emergency medical team }\end{array}$ \\
\hline $\begin{array}{l}\text { Hypotension and } \\
\text { tachycardia (fast pulse) }\end{array}$ & Vasodilation & $\begin{array}{l}\text { Oxygen saturation, } \\
\text { pulse, BP }\end{array}$ & $\begin{array}{l}\text { Elevate legs } 60^{\circ} \text {; oxygen, } 6-10 \mathrm{~L} / \mathrm{min} \text {; rapid } \\
\text { intravenous fluids; epinephrine }(1: 10,000) \text {, } \\
1 \mathrm{~mL} \text { intravenously (slowly); call the emergency } \\
\text { medical team }\end{array}$ \\
\hline $\begin{array}{l}\text { Hypotension and } \\
\text { bradycardia (slow pulse) }\end{array}$ & Vasovagal response & $\begin{array}{l}\text { Oxygen saturation, } \\
\text { pulse, BP }\end{array}$ & $\begin{array}{l}\text { Elevate legs } 60^{\circ} \text {; oxygen, } 6-10 \mathrm{~L} / \mathrm{min} \text {; atropine, } \\
0.6-1 \mathrm{mg} \text { intravenously (slowly); repeat to } \\
\text { total of } 2-3 \mathrm{mg}(0.04 \mathrm{mg} / \mathrm{kg}) \text { if needed; call the } \\
\text { emergency medical team }\end{array}$ \\
\hline \multicolumn{4}{|l|}{ Nonanaphylactoid } \\
\hline Cardiac arrhythmia & $\begin{array}{l}\text { Ionic abnormalities; } \\
\text { chemical variations }\end{array}$ & $\begin{array}{l}\text { Oxygen saturation, } \\
\text { pulse, BP, ECG }\end{array}$ & $\begin{array}{l}\text { Follow } \mathrm{ACLS}^{*} \text { protocols; call the emergency } \\
\text { medical team }\end{array}$ \\
\hline Hypertension & $\begin{array}{l}\text { Histamine release of } \\
\text { catecholamine }\end{array}$ & $\begin{array}{l}\text { Oxygen saturation, } \\
\text { pulse, BP, ECG }\end{array}$ & $\begin{array}{l}\text { Nitroglycerine, } 0.4 \mathrm{mg} \text { sublingually; } \\
\text { nitroglycerine; } 2 \% \text { ointment; phentolamine, } \\
5 \mathrm{mg} \text { intravenously for pheochromocytoma; } \\
\text { call the emergency medical team }\end{array}$ \\
\hline Seizures & $\begin{array}{l}\text { Ionic abnormalities; } \\
\text { chemical variations }\end{array}$ & $\begin{array}{l}\text { Oxygen saturation, } \\
\text { pulse, BP, ECG }\end{array}$ & $\begin{array}{l}\text { Secure airway; oxygen, } 6-10 \mathrm{~L} / \mathrm{min} \text {; diazepam, } \\
5 \mathrm{mg} \text { intramuscularly/intravenously; } \\
\text { midazolam, } 0.5-1 \mathrm{mg} \text { intravenously; } \\
\text { phenytoin infusion, } 15-18 \mathrm{mg} / \mathrm{kg} \text { at } \\
50 \mathrm{mg} / \mathrm{min} \text {; call the emergency medical team }\end{array}$ \\
\hline Pulmonary edema & $\begin{array}{l}\text { Osmolar changes, } \\
\text { causing large } \\
\text { fluid volume shifts }\end{array}$ & $\begin{array}{l}\text { Oxygen saturation, } \\
\text { pulse, BP, ECG }\end{array}$ & $\begin{array}{l}\text { Secure airway; oxygen, } 6-10 \mathrm{~L} / \mathrm{min} \text {; furosemide, } \\
20-40 \mathrm{mg} \text { intravenously (slowly); morphine, } \\
1-3 \mathrm{mg} \text { intravenously; call the emergency } \\
\text { medical team }\end{array}$ \\
\hline
\end{tabular}

All medications are to be administered under physician supervision. BP = blood pressure; ECG = electrocardiogram; $A C L S=$ advanced cardiovascular life support.

media usually produce a local inflammatory response in the skin, without serious sequela. Larger volumes $(50-75 \mathrm{~mL})$ may produce tissue damage from chemotoxicity or resultant compartment syndrome $(19,20)$.

Patients usually present with persistent burning and swelling at the injection site. Assessment of the patient's pulse distal to the injection site and documentation of initial swelling and erythema are essential in early management. Smaller extravasations may be managed with elevation and cold compresses. In cases with persistent swelling, pain, and discoloration, it is best to consult a surgeon. Complications of contrast extravasation tend to be more severe with higher-osmolality contrast agents $(19,21,22)$.

\section{Air Embolism}

Air embolism is a potentially fatal but rare complication of intravenous contrast injection. Symptoms include dyspnea, cough, chest pain, pulmonary edema, hypotension, and neurologic deficit. Treatment includes administering 100\% oxygen and placing the patient in a left lateral decubitus (left side down) position and, if needed, providing hyperbaric oxygen $(23-27)$.

\section{Additional Reactions}

Contrast reactions are classified as mild (which are usually self-limiting and resolve quickly with reassurance and without additional intervention), moderate (which take 
TABLE 6

Suggested Supplies and Information to Be Made Available

\begin{tabular}{cc}
\hline \multicolumn{1}{c}{ Category } & \multicolumn{1}{c}{ Specifics } \\
\hline $\begin{array}{c}\text { Posted } \\
\text { information }\end{array}$ & $\begin{array}{c}\text { Name and contact information for } \\
\text { physician on duty, phone number } \\
\text { of emergency response team } \\
\text { Oxygen cylinders, flow valves, tubing, } \\
\text { apparatus } \\
\text { nasal prongs, oxygen masks (adult } \\
\text { and pediatric sizes), bag-valve mask, } \\
\text { valve masks, endotracheal tubes, } \\
\text { laryngoscopes, intravenous fluids } \\
\text { (normal saline, Ringer's lactate) }\end{array}$ \\
$\begin{array}{c}\text { Defibrillator, ECG, blood pressure/ } \\
\text { pulse monitor, pulse oximeter } \\
\text { monitoring } \\
\text { devices }\end{array}$ & $\begin{array}{c}\text { Epinephrine, 1:10,000, 10-mL preloaded } \\
\text { syringe; epinephrine, 1:1,000, 1-mL } \\
\text { preloaded syringe; atropine, 1 mg in }\end{array}$ \\
& $\begin{array}{c}\text { 10-mL preloaded syringe; } \beta \text {-agonist } \\
\text { inhaler; diphenhydramine for } \\
\text { intramuscular/intravenous injection; }\end{array}$ \\
& nitroglycerin, 0.4-mg tabs, sublingually \\
& \\
\hline ECG = electrocardiogram.
\end{tabular}

longer to resolve and may progress; these usually require medical intervention), and severe (which are life-threatening and always require medical intervention).

Management of contrast reactions follows the lines of usual resuscitation measures used in current medical practice. A detailed description of managing contrast reactions is beyond the scope of this article, but the basic principles of their management and some common management strategies have been summarized in Tables 4 and $5(1,5,28-31)$. Guidelines for suggested medications and information to be displayed where contrast would be administered are summarized in Table 6.

\section{SPECIAL SITUATIONS}

\section{Delayed Reactions}

Delayed reactions occur between $1 \mathrm{~h}$ and $7 \mathrm{~d}$ after injection of contrast in approximately $2 \%$ of patients (31). Common delayed reactions are flulike symptoms (fever, chills, rashes, pruritus, and nausea). Less-frequent manifestations are parotitis, joint pain, and depression. Many of these are not considered to be related to contrast media at all, but the skin rashes have been attributed to contrast media (31). Delayed reactions are more common in patients with interleukin-2 chemotherapy and in those injected with nonionic dimers $(31,32)$. The reactions usually resolve spontaneously and are treated with supportive therapy: analgesics to treat headaches, antipyretics for fever, meperidine for rigors, and isotonic fluid for hypotension.

\section{Contrast-Induced Nephrotoxicity}

Contrast agent-related nephropathy is an elevation of the serum creatinine level by more than $0.5 \mathrm{mg} / \mathrm{dL}$ or more than $50 \%$ of baseline 1-3 d after contrast injection. The incidence of contrast agent-related nephropathy is estimated to be $2 \%-7 \%(33,34)$. Causes for contrast-induced nephrotoxicity include renal hemodynamic changes resulting in renal vasoconstriction or direct contrast-induced tubular toxicity. Risk factors of and methods for preventing contrast-induced nephropathy are summarized in Table 7. The risks and benefits of nephrotoxicity must be weighed carefully before administration of intravenous contrast in these situations. Contrast-induced nephrotoxicity is best handled by a nephrologist.

Non-insulin-dependent patients with diabetes who are on biguanide therapy (metformin, glyburide, glucophage, and metaglip) are at particular risk of contrast-induced nephrotoxicity. Medications must be stopped immediately after the contrast injection, and they should be restarted by the primary physician $48 \mathrm{~h}$ later only after confirmation of normal renal and liver function tests (35).

\section{Pregnant and Nursing Patients}

The safety of intravenous iodinated contrast media during pregnancy has not been established. Contrast media can cross the placenta, enter fetal circulation, and cause thyroid disorders (36-39). Intravenous contrast should be used in pregnancy only if the possible benefits outweigh the risks. Any elective examination requiring intravenous contrast should be deferred until the postpartum period. There is now believed to be an extremely low passage of contrast into the fetal circulation, of which a very small amount is actually absorbed by the infant; although some mothers may cease breast-feeding for $24 \mathrm{~h}$ after contrast administration, the basis for this practice is questioned (39).

TABLE 7

Risk Factors for and Methods to Prevent Contrast-Induced Nephrotoxicity

Risk factor

Advanced age, antibiotics (aminoglycosides such as gentamycin), cardiovascular disease, chemotherapy, collagen vascular diseases, elevated serum creatinine levels (variable levels, 1.3-2.0 mg/dL), dehydration, diabetes (insulin-dependent $>2 \mathrm{y}$; non-insulin-dependent $>5 \mathrm{y}$ ), nonsteroidal antiinflammatory medications, paraproteinemias (myeloma), renal disease, kidney transplant
Method

Use the smallest amount of contrast material possible; discontinue other nephrotoxic medications before the procedure; maintain adequate interval between procedures requiring contrast material; maintain hydration (oral, $500 \mathrm{~mL}$ before the procedure and $2,500 \mathrm{~mL}$ during the $24 \mathrm{~h}$ after the procedure; intravenous, $0.9 \%$ or $0.45 \%$ saline, $100 \mathrm{~mL} / \mathrm{h}$, beginning $4 \mathrm{~h}$ before the procedure and continuing for the $24 \mathrm{~h}$ after the procedure) 


\section{CONTRAST REACTIONS IN CHILDREN}

Pediatric contrast reactions are usually anaphylactoid but mild, with reported rates of $0.18 \%$ for LOCM and $3 \%$ for HOCM $(40,41)$. Reactions are harder to detect in children than in adults, as children may not be able to communicate their symptoms. Management of pediatric contrast reactions is similar to management in adults, but with age-appropriate dosing. A special pediatric code chart with appropriate doses and equipment should be maintained $(42,43)$.

\section{REACTIONS TO ORAL CONTRAST}

Rarely, anaphylactoid reactions have been attributed to oral contrast media, but these are mostly limited to case reports (44-47).

\section{CONCLUSION}

Iodinated contrast media are frequently used and are safe. Reactions, when they occur, are usually mild but may occasionally progress to life-threatening proportions. A thorough understanding of the etiology, predisposing factors, symptoms, and management strategies is effective in minimizing the threat posed by these factors.

\section{REFERENCES}

1. American College of Radiology Manual on Contrast Media. 4th ed. Reston, VA: American College of Radiology; 1998.

2. Costa N. Understanding contrast media. J Infus Nurs. 2004;27:302-312.

3. Bettmann MA, Morris TW. Recent advances in contrast agents. Radiol Clin North Am. 1986;24:347-357.

4. Cochran ST, Bomyea K, Sayre JW. Trends in adverse events after IV administration of contrast media. AJR. 2001;176:1385-1388.

5. Namasivayam S, Kalra MK, Torres WE, Small WC. Adverse reactions to intravenous iodinated contrast media: an update. Curr Probl Diagn Radiol. 2006;35: 164-169.

6. Morcos SK, Thomsen HS. Adverse reactions to iodinated contrast media. Eur Radiol. 2001;11:1267-1275.

7. Bush WH, Swanson DP. Acute reactions to intravascular contrast media: types, risk factors, recognition, and specific treatment. AJR. 1991;157:1153-1161.

8. Bettmann MA, Holzer JF, Trombly ST. Risk management issues related to the use of contrast agents. Radiology. 1990;175:629-631.

9. Delaney A, Carter A, Fisher M. The prevention of anaphylactoid reactions to iodinated radiological contrast media: a systematic review [abstract]. BMC Med Imaging. 2006;6:2

10. Almen T. The etiology of contrast medium reactions. Invest Radiol. 1994; 29(suppl 1):S37-S45.

11. Cochran ST. Anaphylactoid reactions to radiocontrast media. Curr Allergy Asthma Rep. 2005;5:28-31.

12. Laroche D, Namour F, Lefrançois C, et al. Anaphylactoid and anaphylactic reactions to iodinated contrast material. Allergy. 1999;54(suppl 58):13-16.

13. Katzberg R. The contrast media manual. In: McCance KL, Huether SE, eds. Pathophysiology: The Biologic Basis for Disease in Adults and Children. St. Louis, MO: Mosby; 1992.

14. Limbruno U, De Caterina R. Vasomotor effects of iodinated contrast media: just side effects? Curr Vasc Pharmacol. 2003;1:321-328.

15. Tramer MR, von Elm E, Loubeyre P, Hauser C. Pharmacological prevention of serious anaphylactic reactions due to iodinated contrast media: systematic review. BMJ. 2006;333:675.

16. Konen E, Konen O, Katz M, Levy Y, Rozenman J, Hertz M. Are referring clinicians aware of patients at risk from intravenous injection of iodinated contrast media? Clin Radiol. 2002;57:132-135.
17. Lasser EC, Berry CC, Mishkin MM, Williamson B, Zheutlin N, Silverman JM. Pretreatment with corticosteroids to prevent adverse reactions to nonionic contrast media. AJR. 1994;162:523-526.

18. Seymour R, Halpin SF, Hardman JA. Corticosteroid pretreatment and nonionic contrast media. AJR. 1995;164:508-509.

19. Wang CL, Cohan RH, Ellis JH, Adusumilli S, Dunnick NR. Frequency, management, and outcome of extravasation of nonionic iodinated contrast medium in 69,657 intravenous injections. Radiology. 2007;243:80-87.

20. Federle MP, Chang PJ, Confer S, Ozgun B. Frequency and effects of extravasation of ionic and nonionic CT contrast media during rapid bolus injection. Radiology. 1998;206:637-640.

21. Selek H, Ozer H, Aygencel G, Turanli S. Compartment syndrome in the hand due to extravasation of contrast material. Arch Orthop Trauma Surg. 2007;127:425-427.

22. Schaverien MV, Evison D, McCulley SJ. Management of large volume CT contrast medium extravasation injury: technical refinement and literature review. J Plast Reconstr Aesthet Surg. April 23, 2007 [Epub ahead of print].

23. Husain S, Ahmed L, Al-Sawwaf M. Venous air embolism from intravenous CT contrast administration. J Am Coll Surg. 2006;202:197.

24. Athar MK, Islam T, Grammes J, Athar MN. Near-fatal pulmonary air embolus from iatrogenic injection of air during contrast administration. QJM. 2005;98:231-232.

25. Imai S, Tamada T, Gyoten M, Yamashita T, Kajihara Y. Iatrogenic venous air embolism caused by CT injector: from a risk management point of view. Radiat Med. 2004;22:269-271.

26. Wald M, Kirchner L, Lawrenz K, Amann G. Fatal air embolism in an extremely low birth weight infant: can it be caused by intravenous injections during resuscitation? Intensive Care Med. 2003;29:630-633.

27. Ie SR, Rozans MH, Szerlip HM. Air embolism after intravenous injection of contrast material. South Med J. 1999;92:930-933.

28. American Heart Association (AHA). ACLS: Principles and Practice. Dallas, TX: AHA; 2003.

29. American Heart Association (AHA). Advanced Cardiovascular Life Support Provider Manual. Dallas, TX: AHA; 2006.

30. Stiell IG, Spaite DW, Field B, et al. Advanced life support for out-of-hospital respiratory distress. $N$ Engl J Med. 2007;356:2156-2164.

31. Webb JA, Stacul F, Thomsen HS, et al. Late adverse reactions to intravascular iodinated contrast media. Eur Radiol. 2003;13:181-184.

32. Choyke PL, Miller DL, Lotze MT, Whiteis JM, Ebbitt B, Rosenberg SA. Delayed reactions to contrast media after interleukin-2 immunotherapy. Radiology. 1992;183:111-114.

33. Barrett BJ. Contrast nephrotoxicity. J Am Soc Nephrol. 1994;5:125-137.

34. Barrett BJ, Carlisle EJ. Metaanalysis of the relative nephrotoxicity of high- and low-osmolality iodinated contrast media. Radiology. 1993;188:171-178.

35. Sayer JA. Acute renal failure from contrast medium: beware patients taking metformin. BMJ. 2006;333:653.

36. Hill BJ, Saigal G, Patel S, Abdenour GE Jr. Transplacental passage of non-ionic contrast agents resulting in fetal bowel opacification: a mimic of pneumoperitoneum in the newborn. Pediatr Radiol. 2007;37:396-398.

37. Vanhaesebrouck P, Verstraete AG, De Praeter C, Smets K, Zecic A, Craen M. Transplacental passage of a nonionic contrast agent. Eur J Pediatr. 2005;164:408-410.

38. Moon AJ, Katzberg RW, Sherman MP. Transplacental passage of iohexol. J Pediatr. 2000; $136: 548-549$

39. Webb JA, Thomsen HS, Morcos SK. The use of iodinated and gadolinium contrast media during pregnancy and lactation. Eur Radiol. 2005;15:1234-1240.

40. Yunginger JW. Anaphylaxis. Curr Probl Pediatr. 1992;22:130-146.

41. Dillman JR, Strouse PJ, Ellis JH, Cohan RH, Jan SC. Incidence and severity of acute allergic-like reactions to i.v. nonionic iodinated contrast material in children. AJR. 2007;188:1643-1647.

42. Lubitz DS, Seidel JS, Chameides L, Luten RC, Zaritsky AL, Campbell FW. A rapid method for estimating weight and resuscitation drug dosages from length in the pediatric age group. Ann Emerg Med. 1988;17:576-581.

43. Ralston M, Hazinski MF, Zaritsky AL, Schexnayder SM, Kleinman ME. Pediatric Advanced Life Support: Provider Manual. Dallas, TX: American Heart Association; 2006.

44. Seymour CW, Pryor JP, Gupta R, Schwab CW. Anaphylactoid reaction to oral contrast for computed tomography. J Trauma. 2004;57:1105-1107.

45. Miller SH. Anaphylactoid reaction after oral administration of diatrizoate meglumine and diatrizoate sodium solution. AJR. 1997;168:959-961.

46. Wolf GL, Mishkin MM, Roux SG, et al. Comparison of the rates of adverse drug reactions: ionic contrast agents, ionic agents combined with steroids, and nonionic agents. Invest Radiol. 1991;26:404-410.

47. Armen RN, Cohen SG, Kantor M. Anaphylactoid reaction following the oral administration of iodide-containing cholecystographic media. J Allergy. 1956;27: 544-547. 